This document is confidential and is proprietary to the American Chemical Society and its authors. Do not copy or disclose without written permission. If you have received this item in error, notify the sender and delete all copies.

\title{
Synthesis of cellulose nanocrystals carrying tyrosine sulfate mimetic ligands and inhibition of alphavirus infection
}

\begin{tabular}{|r|l|}
\hline Journal: & Biomacromolecules \\
\hline Manuscript ID: & bm-2014-00229d.R1 \\
\hline Manuscript Type: & Article \\
\hline Date Submitted by the Author: & n/a \\
\hline Complete List of Authors: & $\begin{array}{l}\text { Zoppe, Justin; Aalto University, Department of Biotechnology \& Chemical } \\
\text { Technology } \\
\text { Ruottinen, Ville; University of Eastern Finland, School of Pharmacy, Faculty } \\
\text { of Health Sciences } \\
\text { Ruotsalainen, Janne; University of Eastern Finland, A. I. Virtanen Institute } \\
\text { for Molecular Sciences, Faculty of Health Sciences } \\
\text { Rönkö, Seppo; University of Eastern Finland, School of Pharmacy, Faculty } \\
\text { of Health Sciences } \\
\text { Johansson, Leena-Sisko; Aalto University, Department of Forest Products } \\
\text { Technology } \\
\text { Hinkkanen, Ari; University of Eastern Finland, A. I. Virtanen Institute for } \\
\text { Molecular Sciences, Faculty of Health Sciences } \\
\text { Järvinen, Kristina; University of Eastern Finland, School of Pharmacy, } \\
\text { Faculty of Health Sciences } \\
\text { Seppälä, Jukka; Aalto University, Biotechnology and Chemical Technology }\end{array}$ \\
\hline
\end{tabular}




\title{
Synthesis of cellulose nanocrystals carrying tyrosine
}

\section{sulfate mimetic ligands and inhibition of alphavirus}

\author{
infection
}

Justin O. Zoppe, ${ }^{\dagger} *$ Ville Ruottinen, ${ }^{\ddagger}$ Janne Ruotsalainen, ${ }^{\#}$ Seppo Rönkkö, ${ }^{\ddagger}$

Leena-Sisko Johansson, ${ }^{\ominus}$ Ari Hinkkanen, ${ }^{\#}$ Kristiina Järvinen, ${ }^{\ddagger}$ and Jukka

Seppälä̈,*

${ }^{\dagger}$ Polymer Technology, Department of Biotechnology \& Chemical Technology, Aalto University

School of Chemical Technology, P.O. Box 16100, 00076 Aalto, Finland

${ }^{\diamond}$ Department of Forest Products Technology, Aalto University School of Chemical Technology, P.O. Box 16300, 00076 Aalto, Finland

łUniversity of Eastern Finland, School of Pharmacy, Faculty of Health Sciences, 70211 Kuopio, Finland

${ }^{\#}$ A. I. Virtanen Institute for Molecular Sciences, Faculty of Health Sciences, University of Eastern Finland, 70211 Kuopio, Finland

*Corresponding authors: E-mail: jozoppe@gmail.com, jukka.seppala@aalto.fi, Phone: +358 40070 1142, Fax: +3589462373

\begin{abstract}
KEYWORDS. Cellulose nanocrystals, whiskers, tyrosine sulfate mimetics, multivalent nanoparticles, polyanionic inhibitor, antiviral, Semliki Forest virus, alphavirus.
\end{abstract}




\begin{abstract}
We present two facile approaches for introducing multivalent displays of tyrosine sulfate mimetic ligands on the surface of cellulose nanocrystals (CNCs) for application as viral inhibitors. We tested the efficacy of cellulose nanocrystals, prepared either from cotton fibers or Whatman filter paper, to inhibit alphavirus infectivity in Vero (B) cells. Cellulose nanocrystals were produced by sulfuric acid hydrolysis leading to nanocrystal surfaces decorated with anionic sulfate groups. When the fluorescent marker expressing Semliki Forest virus vector, VA7-EGFP, was incubated with CNCs, strong inhibition of virus infectivity was achieved, up to $100 \%$ and $88 \%$ for cotton and Whatman CNCs, respectively. When surface sulfate groups of CNCs were exchanged for tyrosine sulfate mimetic groups (i.e. phenyl sulfonates), improved viral inhibition was attained. Our observations suggest that conjugation of target-specific functionalities to CNC surfaces provides a means to control their antiviral activity. Multivalent CNCs did not cause observable in vitro cytotoxicity to Vero (B) cells or human corneal epithelial (HCE-T) cells, even within the $100 \%$ virus-inhibitory concentrations. Based on the similar chemistry of known polyanionic inhibitors, our results suggest the potential application of CNCs as inhibitors of other viruses, such as human immunodeficiency virus (HIV) and Herpes simplex viruses.
\end{abstract}




\section{Introduction}

Over the past few decades, nanotechnology has introduced novel strategies for advanced medical therapy and diagnostics. ${ }^{1} \mathrm{~A}$ distinct benefit of nanoparticles is their similarity in size to biomolecules, such as proteins, therefore their surface chemistry can be tailored with a variety of bioactive compounds for application of nanomedicines. ${ }^{2}$ Here, a single entity can provide multiple binding sites, i.e. display multivalency, and create a high local concentration of binding ligands, so that the equilibrium can be shifted to favor more ligand-receptor complexes. ${ }^{3}$ Thus, nanoparticles can be designed for targeting specific cell types simply by covalent conjugation of small molecules. ${ }^{4}$ In addition, the transformation of inactive monovalent species into highly active therapeutics in the form of multivalent nanoparticles has been recently demonstrated. ${ }^{5-8}$ Such multivalent systems of liposomes, linear polymers, dendrimers and proteins have already been developed. ${ }^{9}$

Gold nanoparticles (AuNPs) have been extensively studied as a substrate for functionalization with bioactive compounds, despite their potential toxicity. ${ }^{10}$ The use of nanoparticles, such as cellulose nanocrystals (CNCs), ${ }^{11,} 12$ that are produced from natural biopolymers, may be a promising alternative to inorganic NPs because of their biodegradability and low degree of cytotoxicity. ${ }^{13,14}$ Powdered cellulose, or microcrystalline cellulose (MCC), has been used as an pharmaceutical excipient in various dosage forms for over 30 years, including tablets, twopiece hard capsules, soft capsules, aqueous suspensions for oral delivery and suppositories. ${ }^{15}$ Cellulose nanocrystals, which are also known as nanocrystalline cellulose (NCC) or cellulose whiskers, have an abundance of hydroxyl functionalities available on the surface for conjugation of binding ligands to create multivalent displays. The use of CNCs as a substrate for fluorescent bioimaging $^{16}$ and controlled release of drugs such as tetracycline, doxorubicin, docetaxel and paclitaxel has been recently presented. ${ }^{17,}{ }^{18}$ However, reports describing the use of CNCs as viral inhibitors are limited. Thus far, the inhibitory effect of CNCs has only been applied to a single model bacteriophage, in which unmodified CNCs derived from tunicates decreased phage infection of host 
E. coli. ${ }^{19}$ Other examples include a multilayered nanofibrous microfiltration (MF) membrane system with high retention capability of bacteria and bacteriophages. Such membrane systems were based on an electrospun polyacrylonitrile (PAN) scaffold impregnated with carboxylated CNCs. ${ }^{20}$ To the best of our knowledge, CNCs produced from sulfuric acid hydrolysis, which contain multivalent displays of anionic sulfate groups on their surfaces, have not been explored as viral inhibitors.

Arthropod-borne (arbo) virus infections are causing debilitating diseases in humans in wide areas of the world. Arbovirus infections cause high morbidity often with long-lasting and debilitating sequelae, including rheumatic and/or neurologic symptoms. In Africa, the Indian subcontinent and in La Reunion Island, Chikungunya alphavirus (CHIK) infections are endemic ${ }^{21}$ and an outbreak recently occurred in Italy due to spread of Aedes albopictus mosquitoes. ${ }^{22}$ In December 2013, the first evidence for the emergence of autochthonous CHIK cases in the Americas were reported, in which about 50 cases were confirmed in the Caribbean islands. ${ }^{23}$ Semliki Forest virus (SFV), closely related to CHIK, is an alphavirus extensively studied as a model for analyzing entry of enveloped viruses into target cells. ${ }^{24,} 25$ Tyrosine sulfate-mediated interactions play a crucial role in HIV-1 entry, ${ }^{26}$ nevertheless tyrosine sulfate mimetics ${ }^{27}$ may also be advantageous against alphavirus infections. ${ }^{28-30}$

The aim of the present study was to design and synthesize CNCs carrying multivalent displays of tyrosine sulfate mimetic ligands and evalute their efficacy to inhibit alphavirus infection. At first, CNCs were produced by sulfuric acid hydrolysis leading to nanocrystal surfaces decorated with anionic sulfate groups. Surface sulfate groups of CNCs were hydrolytically removed and phenyl sulfonate groups were introduced via direct surface conjugation with 4-sulfophenyl isothiocyanante (4-SPITC) in aqueous media or via a three-step protocol in organic media including 2,2'(ethylenedioxy)bis(ethylamine) (EBEA) molecular spacers. When the fluorescent marker expressing SFV vector, VA7-EGFP, was incubated with only sulfated CNCs, strong inhibtion of virus infectivity was achieved. Tyrosine sulfate mimetic CNCs displayed improved inhibitory effects against SFV 


\section{Experimental}

Materials. Sulfuric acid (95\%) and acetone (99\%) were purchased from VWR Scientific. Whatman 1 filter paper, dialysis tubing cellulose membrane (MWCO 12,400), 1,1'carbonyldiimidazole, 4-sulfophenyl isothiocyanate sodium salt monohydrate (4-SPITC), 2,2'(ethylenedioxy)bis(ethylamine) (EBEA) and DMSO were all purchased from Sigma-Aldrich.

Preparation of cellulose nanocrystals (CNCs). CNCs were obtained from cotton fibers or Whatman 1 filter paper by acid hydrolysis with $65 \mathrm{wt} \%$ aqueous sulfuric acid solution ( $45^{\circ} \mathrm{C}, 45$ minutes). The resulting dispersion was diluted and filtered into 200 g ice cubes and washed with distilled water until neutral $\mathrm{pH}$ by successive centrifugations at $12,000 \mathrm{rpm}$ at $4{ }^{\circ} \mathrm{C}$ for 20 minutes. Finally, dialysis for one week against distilled water with a 12,400 MWCO dialysis membrane was performed to remove trace amounts of residual sulfuric acid. Concentrations of the resulting CNCs dispersions from various batches were calculated gravimetrically.

Desulfation of cellulose nanocrystals. Removal of sulfate groups derived from sulfuric acid hydrolysis of CNCs was necessary to obtain the maximum number of hydroxyl groups. Following Kloser et al., ${ }^{31} 1 \%$ wt. dispersions of CNCs were treated in $1 \mathrm{M} \mathrm{NaOH}$ at $60{ }^{\circ} \mathrm{C}$ for 5 hours. Subsequently, the reaction is quenched by a 10 -fold dilution with distilled water, centrifuged at $12,000 \mathrm{rpm}$ at $4{ }^{\circ} \mathrm{C}$ for 20 minutes, re-dispersed and dialyzed against distilled water for one week to remove traces of base. In some cases, subsequent reactions were performed with a one-pot procedure immediately following desulfation. 
Synthesis of tyrosine sulfate mimetic cellulose nanocrystals. The procedure to react isothiocyanates directly with CNC hydroxyl groups was adapted from Ferreira et $a .^{32}$ and Nielsen et al. ${ }^{33}$ Immediately following the desulfation reaction, 2.0 molar equiv. of 4-SPITC to anhydroglucose units (AGU) was added and allowed to react at $40{ }^{\circ} \mathrm{C}$ for 20 hours. Subsequently, the reaction was quenched by a 10 -fold dilution with distilled water, centrifuged at $12,000 \mathrm{rpm}$ at $4{ }^{\circ} \mathrm{C}$ for 20 minutes, re-dispersed and dialyzed against distilled water for one week to remove residual reactants and traces of base. These samples were referred to as cotton-SPTC.

Synthesis of tyrosine sulfate mimetic cellulose nanocrystals containing 2,2'(ethylenedioxy)bis(ethylamine) (EBEA) molecular spacers. ${ }^{34}$ After the desulfation reaction, CNCs was solvent-exchanged from water to acetone to anhydrous dimethyl sulfoxide (DMSO) by successive centrifugations at $12,000 \mathrm{rpm}$ at $4{ }^{\circ} \mathrm{C}$ for 20 minutes. Under nitrogen atmosphere, 1,1'carbonyldiimidazole (CDI) was added to the reaction mixture and stirred at $40{ }^{\circ} \mathrm{C}$ for 20 hours. Then, the reaction was diluted, centrifuged and re-dispersed in DMSO. Subsequently, EBEA was added and reacted at $40^{\circ} \mathrm{C}$ for 20 hours. Again, the reaction was diluted, centrifuged and re-dispersed in DMSO. Then, 4-SPITC was added and reacted at $40{ }^{\circ} \mathrm{C}$ for another 20 hours. The products were then collected by centrifugation, re-dispersed in water and dialyzed for one week. These samples were referred to as cotton-EBEA.

Dynamic Light Scattering (DLS). The particle sizes of CNCs derived from cotton fiber and Whatman filter paper were determined via dynamic light scattering (Zetasizer Nano ZS, Malvern Instruments) at a detection angle of $173^{\circ}$. CNCs dispersions were diluted to $0.05 \%$ wt. in disposable polystyrene cuvettes and a desired amount of $\mathrm{NaCl}$ was added to a final concentration of $1 \mathrm{mM}$. Samples were sonicated for 10 minutes prior to measurements at $25{ }^{\circ} \mathrm{C}$. Results of DLS were interpreted in terms of equivalent spherical hydrodynamic diameters. Here, the equivalent spherical hydrodynamic diameter of rod-shaped nanoparticles is the diameter of spherical nanoparticles with the same translational diffusion coefficient. 
Conductometric titration. To determine the number of acid groups on CNC surfaces, conductometric titration was performed according to established methods. ${ }^{35}$ After dialysis, CNC dispersions were diluted to a concentration of $0.1 \%$ wt. with deionized water and a desired amount of $\mathrm{NaCl}$ was added to a final concentration of $1 \mathrm{mM}$. The conductometric titration was performed with a titrator 751 GPD Titrino (Metrohm AG, Herisau, Switzerland) by adding $0.02 \mathrm{~mL}$ of $0.1 \mathrm{M}$ $\mathrm{NaOH}$ using $30 \mathrm{~s}$ intervals under continuous stirring.

Attenuated Total Reflectance-Fourier Transform Infrared Spectroscopy (ATR-FTIR). Infrared spectra were obtained in order to confirm surface chemical modifications of CNCs. Dried samples were directly analyzed in a Mattson 3000 FTIR spectrometer equipped with a Pike Technologies GladiATR accessory. All spectra were collected with a $2 \mathrm{~cm}^{-1}$ resolution after 32 continuous scans.

X-Ray Photoelectron Spectroscopy. XPS measurements were performed on freeze-dried samples of CNCs before and after surface modifications with an AXIS 165 electron spectrometer and monochromatic Al irradiation. Samples were placed in the spectrometer and evacuated overnight in order to stabilize vacuum conditions. All samples were measured at three locations on the surface (analysis area of ca. $1 \mathrm{~mm}^{2}$ ) and the average values were reported. Elemental surface compositions were determined from low-resolution scans recorded with an $80 \mathrm{eV}$ analyzer pass energy and a $1 \mathrm{eV}$ step. Carbon high-resolution spectra were recorded at binding energies in the $\mathrm{C} 1 \mathrm{~s}$ region using 20 $\mathrm{eV}$ analyzer pass energy and $0.1 \mathrm{eV}$ step. In the curve fitting procedure for $\mathrm{C} 1 \mathrm{~s}$, symmetric Gaussian components with Shirley background were used. ${ }^{36,37}$ The binding energy scale was shifted using the C-C binding energy at $285.0 \mathrm{eV} .^{38}$ Whatman filter paper was used as reference for $100 \%$ cellulose.

Alphavirus infectivity inhibition assay. CNCs were prepared in $10 \mathrm{mM}$ Tris- $\mathrm{HCl}$ and the $\mathrm{pH}$ adjusted to neutral range using sterile filtered $1 \mathrm{M}$ Tris-HCl (pH 7.8). Using sterile filtered $10 \mathrm{mM}$ Tris-HCl (pH 7.8) the CNCs samples were then adjusted to the right work stock concentration. Semliki Forest virus vector, VA7-EGFP or rA774, was diluted using 10 mM Tris-HCl (pH 7.8) buffer 
so that the titer of resulting work stock was $1 \times 10^{5} \mathrm{PFU} / \mathrm{mL}$. The prepared CNCs and the virus work stocks were mixed 1:1 (100 $\mu \mathrm{l}+100 \mu \mathrm{l}$ volumes) and incubated at $4{ }^{\circ} \mathrm{C} \mathrm{O} / \mathrm{N}$ before final virus titering on Vero (B) cells using standard plaque assay. ${ }^{39}$ As a sham control, pure $10 \mathrm{mM}$ Tris-HCl buffer (pH 7.8) was used. To ensure that the antiviral activity of CNC samples was not due to cytotoxicity, Vero (B) cells were treated with the CNC samples overnight. After 24 hours, cells were washed with phosphate buffer solution (PBS) followed by infection with VA7-EGFP.

Cell viability assay. The cell toxicity of CNCs samples was assayed using a standard cell viability method. The immortalization of human corneal epithelial (HCE-T) cells has been reported earlier by Araki-Sasaki et al. ${ }^{40}$ HCE-T cells were cultured in standard complete growth medium as described earlier by Toropainen et al. ${ }^{41}$ and passage numbers 37-41 were used for cell viability assays. HCE-T cells were seeded at density of 10000 cells per well in 96-well tissue-culture plates (Corning Inc., Corning, NY, USA) and they were left overnight to attach onto plates. The cells were treated both with undiluted and with culture medium diluted test solutions (CNC samples, negative control) for 1 hour $(n=4)$. Test solutions were removed by washing cells twice with Hank's buffer salt solution (HBSS) before addition of assay reagents. Cell viability was measured by using the CellTiter-Blue ${ }^{\mathrm{TM}}$ assay (Promega Corporation, Madison, WI, USA), which is a fluorometric assay based on the ability of viable cells to convert resazurin (redox dye) into fluorescent product resorufin. CellTiter-Blue ${ }^{\mathrm{TM}}$ reagent (20 $\mu$ l per well) and HBSS (100 $\mu$ l per well) were first mixed together and the mixture so formed was added to HCE-T cells. The assay plates were incubated at $37^{\circ} \mathrm{C}$ in $5 \mathrm{v} / \mathrm{v} \% \mathrm{CO}_{2}$ for $2 \mathrm{~h}$, and fluorescence intensity was recorded by using EnVision 2104 Multilabel Reader (Perkin Elmer) at excitation and emission wavelengths at $560 \mathrm{~nm}$ and $590 \mathrm{~nm}$, respectively. The untreated HCE-T cells served as a negative control and cells treated with a fixative HBSS solution, containing saponin (0.2 v/v \%) and methanol (70 v/v \%), were used as positive (dead) controls. The cell viability was expressed as a percentage (\%) of live cells compared to the unexposed control. 


\section{Results \& Discussion}

It has been known for decades that anionic polysaccharide derivatives, such as cellulose sulfate, have antimicrobial activity against a broad range of microorganisms. ${ }^{42,43}$ Notably, cellulose sulfate reached human phase III clinical trials as a topical microbiocide for prevention of vaginal HIV transmission, but unfortunately adverse effects were observed as users had a higher rate of viral infection compared to the placebo group. ${ }^{44}$ The antiviral activity of such polyanionic compounds are understood to rely heavily on electrostatic interactions with viral envelope glycoproteins. Cellulose nanocrystals (CNCs), produced from sulfuric acid hydrolysis, contain multivalent displays of anionic sulfate groups on their surfaces, and offer a novel platform for the design of multivalent nanostructures for viral inhibition.

Herein, CNCs were produced from cotton fiber and Whatman filter paper by sulfuric acid hydrolysis. Due to the nature of the hydrolysis process, anionic sulfate groups were installed on the nanocrystal surfaces resulting in highly stable aqueous dispersions. Typically, CNCs produced from such sources have widths ranging $\sim 4-7 \mathrm{~nm}$ and lengths of $\sim 100-200 \mathrm{~nm} .{ }^{11,12}$ More detailed physical characterization of CNCs produced by sulfuric acid hydrolysis can be found elsewhere. ${ }^{45}$ In order to compare the relative nanocrystal sizes, samples were analyzed by dynamic light scattering. Results were interpreted in terms of equivalent spherical hydrodynamic diameters, due to the rod-like shape of CNCs. The Z-average particle size of Whatman CNCs was $113 \mathrm{~nm}$, while cotton CNCS was $141 \mathrm{~nm}$. The $\sim 28 \mathrm{~nm}$ larger equivalent diameter of cotton CNCs was most likely a result of larger crystallites present in cotton fiber versus cotton linters; the latter of which is used to produce Whatman filter paper. The total acidic group content of CNCs was determined via conductometric titration. ${ }^{35}$ Results of titrations are summarized in Figure S1 (Supporting Information). Whatman CNCs appeared to have a slightly higher number of acidic groups on a per weight basis compared to cotton CNCs, at 0.29 mequiv/g and 0.22 mequiv/g, respectively. This could have been due to a difference in aspect ratio of cotton versus Whatman CNCs, as supported by the $~ 25 \%$ larger equivalent diameter 
of cotton CNCs determined by DLS. In general, CNCs of smaller size tend to correspond with higher surface charge due to larger surface-to-volume ratio. ${ }^{46}$ The aspect ratio of CNCs produced from cotton varies from about 10 to 30, depending on hydrolysis conditions. ${ }^{11}$ Even though the presence of sulfate groups was desirable for viral entry inhibition, ${ }^{28,42}$ their removal was necessary in order to maximize the number of hydroxyl groups available for further derivatization with tyrosine sulfate mimics. Thus, an established hydrolytic desulfation procedure was carried out under alkali conditions. ${ }^{31}$ After the desulfation reaction of CNCs, the number of acidic groups was significantly reduced to 0.04 mequiv/g, which was comparable to recent literature. ${ }^{31}$

In nature, tyrosine sulfation is a critical post-translational modification associated with high affinity electrostatic interactions in various proteins. ${ }^{47}$ For example, it has been demonstrated that the facilitation of HIV-1 entry into host T-cells and macrophages is via sulfated tyrosines at the N-terminus of chemokine receptor 5 (CCR5). ${ }^{26}$ Subsequently, multivalent nanoparticles with sulfate end groups $^{8}$ and drug-like small molecules containing phenyl sulfonate moieties ${ }^{27}$ have been synthesized to target tyrosine sulfate interactions in a biomimetic manner. Cell surface heparin sulfate mimics have also been designed based on gold ${ }^{5}$ and silver ${ }^{6}$ nanoparticles containing sulfonate moieties, which inhibited Herpes Simplex virus type 1 (HSV-1). Heparin sulfate has also been implicated in the clathrin-mediated endocytosis of SFV. ${ }^{48,49}$ Consequently, the antiviral activity of sulfated polysaccharides was also extended to CHIK and SFV by Briolant et al. ${ }^{28}$ Zhao et al. ${ }^{30}$ demonstrated that a single tyrosine residue within a direct repeat motif of glycoprotein E2 is essential for efficient budding of SFV through the host cell membrane. Later, Skoging et al. ${ }^{29}$ suggested that a pocket of aromatic moieties in the SFV nucleocapsid serve to bind the side chain of the essential E2 tyrosine residue. These findings inspired us to apply tyrosine sulfate mimetics (i.e. phenyl sulfonates) to combat SFV infection, taking advantage of both electrostatic and van der Waals (hydrophobic) interactions, the latter of which appear to be critical for alphavirus capsid assembly. 
In the interest of functionalizing CNCs with tyrosine sulfate mimetic groups, cotton CNC surfaces were derivatized with 4-SPITC one of two pathways (see Scheme 1): either by direct conjugation following the desulfation reaction in an aqueous one-pot procedure, ${ }^{32,33}$ or by a multistep conjugation procedure in DMSO including EBEA as a molecular spacer. ${ }^{34}$ The choice of cotton CNCs instead of Whatman CNCs for surface modifications became clear after preliminary inhibition experiments, which is discussed later.

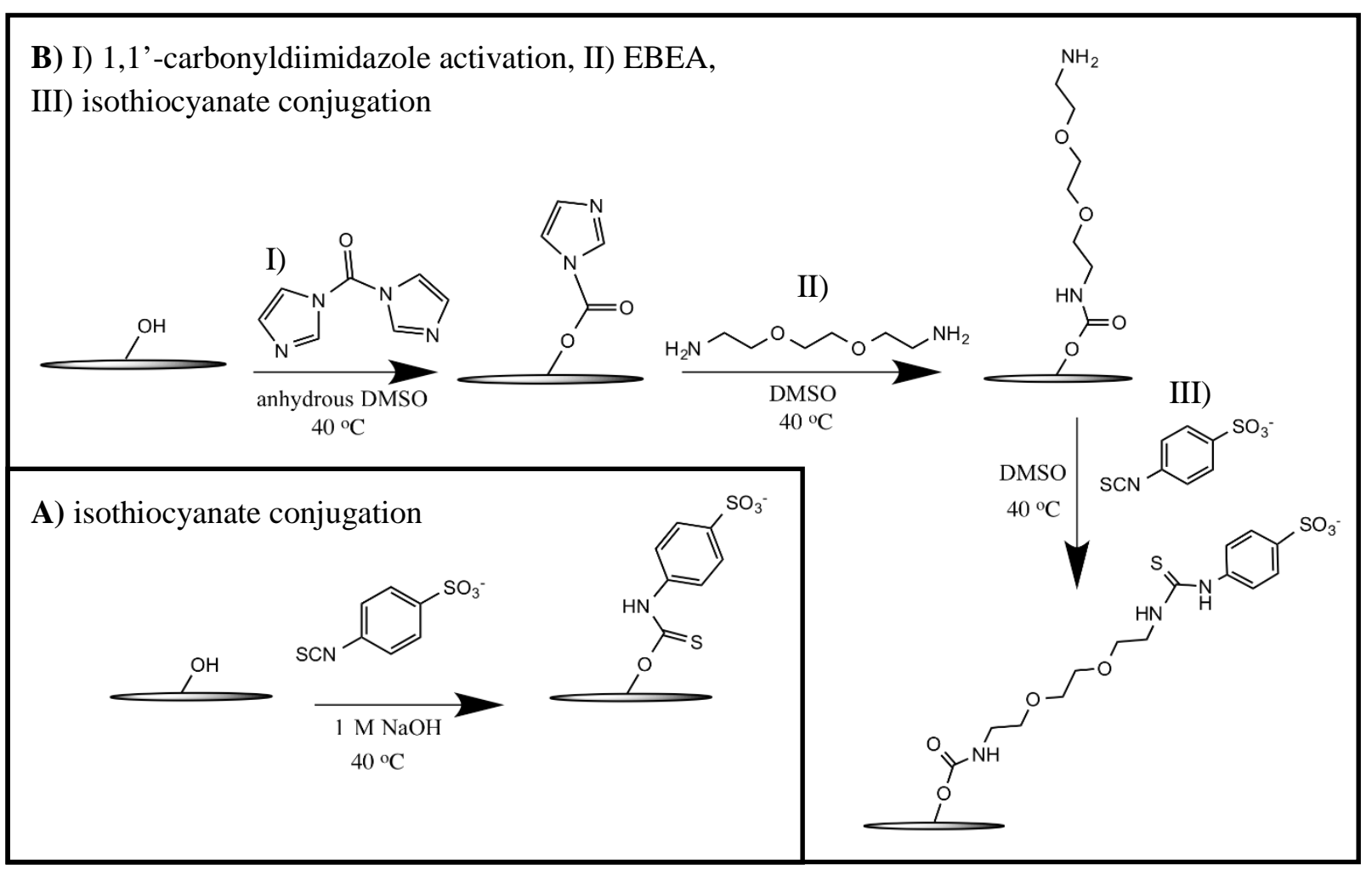

Scheme 1. Synthesis of cellulose nanocrystals carrying tyrosine sulfate mimetic ligands via A) direct surface conjugation of 4-SPITC in aqueous media (cotton-SPTC) or B) conjugation with EBEA molecular spacers in organic media (cotton-EBEA).

To confirm the reaction between 4-SPITC with CNCs hydroxyl groups, lyophilized samples were characterized by ATR-FTIR spectroscopy (Figure 1). In comparison to the spectrum of pristine CNCs, ${ }^{50}$ the spectrum of CNCs conjugated with 4-SPITC (i.e. cotton-SPTC) displayed two new peaks corresponding to the thiocarbamate C-N stretch $\left(1261 \mathrm{~cm}^{-1}\right)$ and an aromatic C-H bend $\left(802 \mathrm{~cm}^{-1}\right)$. Since cotton-SPTC samples were thoroughly dialyzed against deionized water following reactions, these new peaks were taken as an indication of successful surface functionalization. 
Conductometric titrations were also conducted on cotton-SPTC samples (data not presented here), however acidic groups were not detected. It was likely that very low surface hydroxyl substitution was obtained, which was expected due to the low nucleophilicity of hydroxyl groups. As an alternative strategy, activation of hydroxyl groups with 1,1'-carbonyldiimidazole (CDI) in organic media was undertaken. In this case, it was necessary to exchange the solvent of CNCs from water to DMSO after the desulfation reaction via successive centrifugation steps with acetone as an intermediate solvent. Following activation of CNC hydroxyl groups with CDI, amine groups of EBEA were reacted with the resulting ester and released imidazole. Subsequently, the exposed amine nucleophile of CNCs modified with EBEA was reacted with 4-SPITC. Success of the multi-step procedure can be observed in Figure 2, wherein the notable ester stretch $\left(1766 \mathrm{~cm}^{-1}\right)$ indicated successful conjugation of CDI in the first step. After the reaction of EBEA with CDI, a shift in the ester stretch to $1708 \mathrm{~cm}^{-1}$ was observed, which indicated successful release of imidazole. Finally, the reaction of 4-SPITC with the exposed amine group of EBEA was confirmed by an amine bend at $1537 \mathrm{~cm}^{-1}$. Once again, conductometric titrations were also conducted on cotton-EBEA samples (data not presented here) in an attempt to quantify the number of acidic groups. As in the case of cottonSPTC samples, these efforts were unsuccessful most likely due to low degree of surface substitution. Nevertheless, the ATR-FTIR spectra clearly indicated the presence of covalently bound phenyl sulfonate groups, although quantification via conductometric titration remained a challenge. 


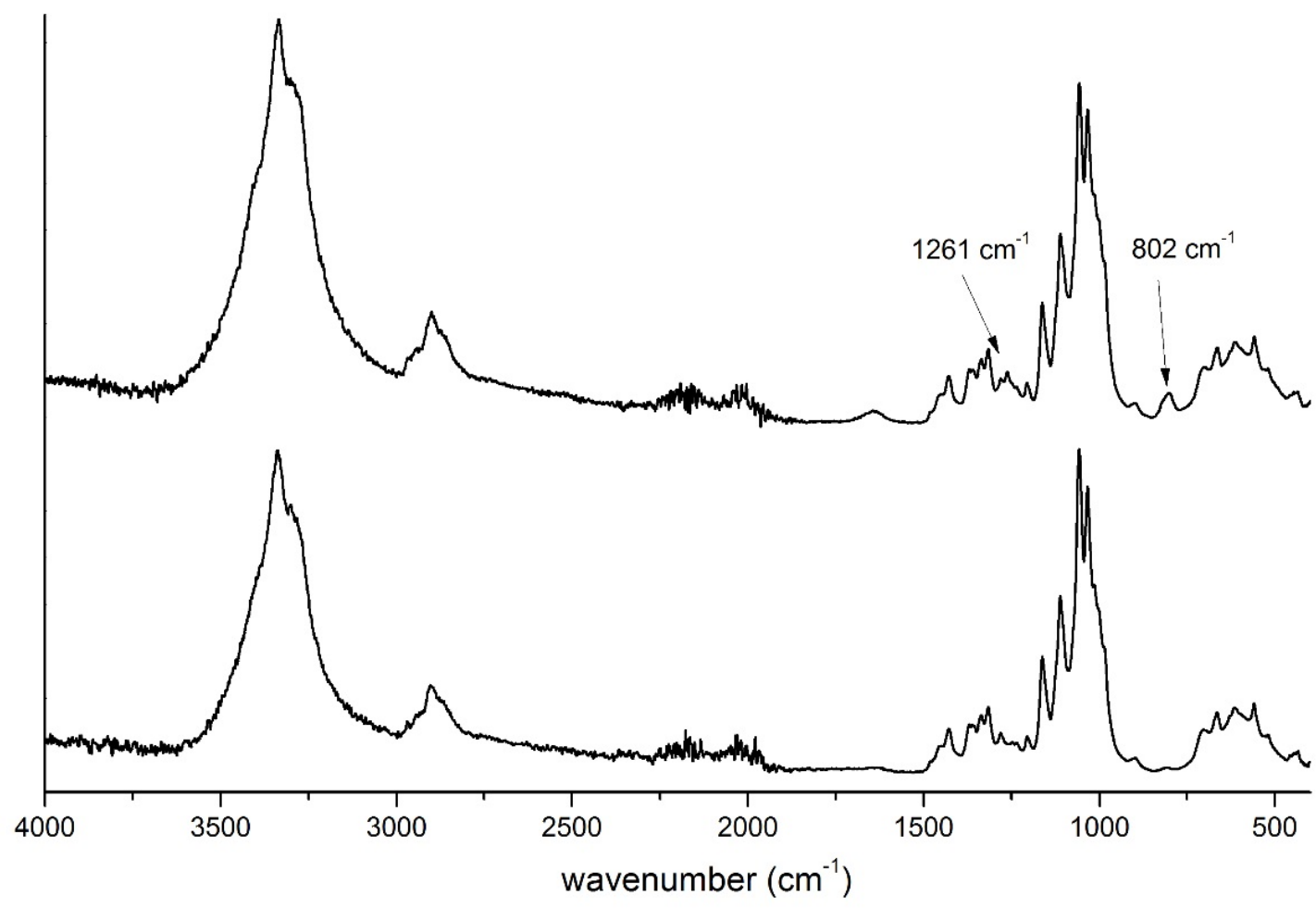

Figure 1. ATR-FTIR spectra of CNCs (bottom) and CNCs functionalized with 4-sulfophenyl isothiocyanate (cotton-SPTC) (top).

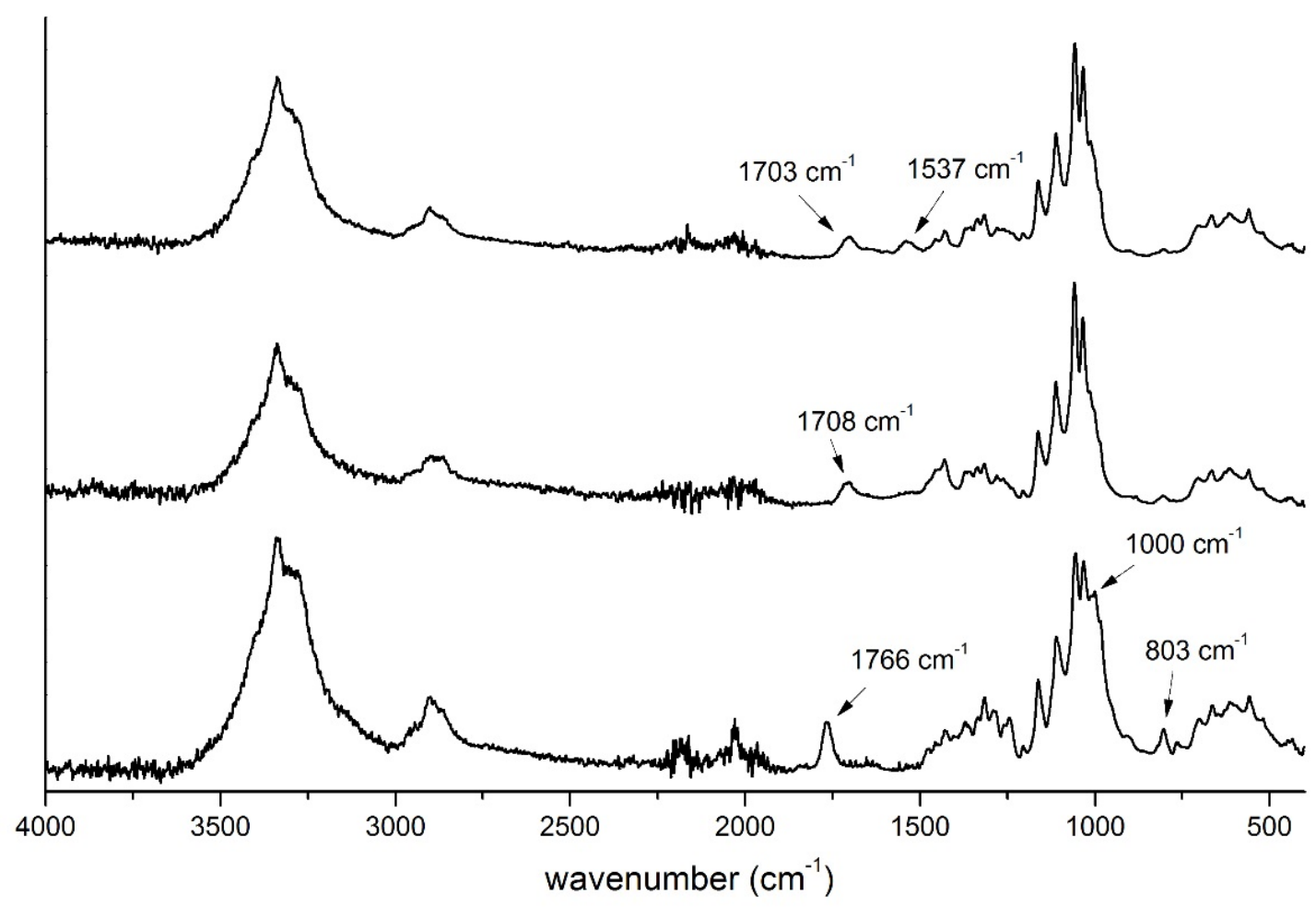

Figure 2. ATR-FTIR spectra of CNCs functionalized with 1,1'-carbonyldiimidazole (bottom), followed by 2,2'-(ethylenedioxy)bis(ethylamine) (middle) followed by 4-sulfophenyl isothiocyanate (cotton-EBEA) (top). 
In efforts to further confirm the presence of phenyl sulfonate groups on the surface of CNCs, XPS experiments were conducted. Lyophilized samples of CNCs were analyzed to give relative intensities of carbon, oxygen, nitrogen and sulfur. Whatman filter paper was used as a reference of pure cellulose. ${ }^{36}$ Table 1 summarizes the surface chemical composition of cotton CNC samples before and after modifications. CNCs produced from sulfuric hydrolysis without further modifications showed the distinctive peaks for carbon and oxygen with a trace sulfur content of 0.3 $\%$ arising from grafted sulfate groups. The ratio of oxygen to carbon $(\mathrm{O} / \mathrm{C})$ was calculated to be 0.75 . Silicon impurities (0.8 \%) were also detected, which could have been attributed to the use of silicone oil baths during synthesis. Some contamination of CNC samples with trace elements was practically unavoidable, ${ }^{36}$ especially since they were exposed to multiple chemicals/surfaces during synthesis and work-up. Cotton CNCs subjected to hydrolytic desulfation showed a notable increase in O/C ratio (0.78), wherein 0.83 is the theoretical value of pure cellulose. ${ }^{37}$ Peaks arising from sulfur did not show a significant decrease as expected, however the presence of silicon impurities (0.8\%) likely masked the true amount of sulfur on pristine CNC surfaces. Another XPS investigation of sulfuric acid hydrolyzed CNCs determined a value of $0.6 \%$ sulfur without the presence of foreign contaminants. ${ }^{51}$ Nevertheless, an $\mathrm{O} / \mathrm{C}$ ratio of 0.78 , which was slightly higher than the Whatman reference value, was an indication that desulfated cotton CNCs were nearly free of surface contaminants. Cotton-SPTC samples showed only a small increase in sulfur content, up to $0.4 \%$, but this was expected based on the results of FTIR (Figure 1) and conductometric titrations. CottonEBEA samples, which were synthesized with CDI activator in DMSO, displayed significant differences in XPS spectra. Notably, the sulfur content increased to $0.6 \%$ and the O/C ratio decreased to 0.68 , which indicated the presence of additional carbon from phenyl and ethylene groups. Most obvious was the increased presence of nitrogen (2.1\%) in Cotton-EBEA samples resulting from the sum of amide and thiourea bonds. Carbon high-resolution spectra of CNC samples were also recorded (shown in Table 2). Compared to desulfated CNCs, the cotton-SPTC samples gave significant 
increases in C1 and C4 peaks, attributed to phenyl and thiocarbamate groups, respectively. As was determined for the survey spectra, the most notable changes were observed for cotton-EBEA samples, in which significant increases in C1 peaks (phenyl and ethylene groups) and C4 peaks (ester and thiourea groups) were observed. Additionally, the ratio of C2/C3 increased to 4.32 for cotton-EBEA due to the presence of ethylene glycol units. Overall, results of XPS confirmed success of surface functionalization of CNCs with phenyl sulfonate groups. The scope of future studies will be to optimize the synthesis of tyrosine sulfate mimetic CNCs in order to obtain more quantifiable degrees of surface substitution via conductometric titrations and/or solid state ${ }^{13} \mathrm{C} \mathrm{CP/MAS} \mathrm{NMR.}$

Table 1. Summary of surface chemical composition of cotton CNCs before and after modifications determined from XPS spectra.

\begin{tabular}{c|ccccccc} 
Sample & O 1s (\%) & C 1s (\%) & Si 2p (\%) & N 1s (\%) & S 2p (\%) & $\begin{array}{c}\text { Na 1s } \\
\mathbf{( \% )}\end{array}$ & O/C \\
\hline Sulfated cotton & 42.4 & 56.8 & 0.8 & - & 0.3 & - & 0.75 \\
Desulfated cotton & 43.5 & 55.7 & 0.1 & 0.1 & 0.3 & 0.3 & 0.78 \\
Cotton-SPTC & 42.8 & 56.4 & 0.4 & 0.1 & 0.4 & - & 0.76 \\
Cotton-EBEA & 39.1 & 57.6 & 0.6 & 2.1 & 0.6 & - & 0.68 \\
Whatman reference & 43.4 & 56.6 & - & - & - & - & 0.77
\end{tabular}

Table 2. Summary of carbon deconvolution of cotton CNCs before and after modifications determined from high resolution XPS spectra.

\begin{tabular}{|c|c|c|c|c|c|}
\hline Sample & $\begin{array}{c}\text { C1 } \\
\text { C-C (\%) }\end{array}$ & $\begin{array}{c}\text { C2 } \\
\text { C-O (\%) }\end{array}$ & $\begin{array}{c}\mathrm{C} 3 \\
\mathrm{C}=\mathrm{O}(\%)\end{array}$ & $\begin{array}{c}\text { C4 } \\
\text { COO } \\
(\%)\end{array}$ & C2/C3 \\
\hline Sulfated cotton & 5.6 & 75.9 & 18.0 & 0.6 & 4.23 \\
\hline Desulfated cotton & 3.0 & 77.6 & 18.7 & 0.7 & 4.15 \\
\hline Cotton-SPTC & 4.0 & 76.5 & 18.6 & 0.9 & 4.12 \\
\hline Cotton-EBEA & 7.8 & 73.3 & 17.0 & 2.0 & 4.32 \\
\hline Whatman reference & 2.3 & 78.3 & 18.7 & 0.8 & 4.19 \\
\hline
\end{tabular}

Presented in Tables S1 and S2 are the raw data of VA7-EGFP inhibition assays (Supporting Information). Assays were performed in $10 \mathrm{mM}$ Tris-HCl buffer and the $\mathrm{pH}$ adjusted to 
7.8 using sterile filtered $1 \mathrm{M}$ Tris-HCl. CNC samples were incubated with VA7-EGFP at various concentrations, while virus concentration was held constant, and final virus titering on Vero (B) cells was performed using a standard plaque assay. ${ }^{39}$ In general, CNCs did not reach effective levels of VA7-EGFP inhibition (i.e. $>50 \%$ ) until concentrations between 0.10 to $0.14 \%$ wt. When diluted, CNCs released the virus, suggesting reversible, concentration-dependent inhibition. In comparison to Whatman CNCs, cotton CNCs showed stronger inhibition, regardless of batch. This result was intriguing since the chemistry of these two classes of CNCs was strikingly similar and higher degree of sulfation has typically led to higher antiviral activity in the case of other sulfated polysaccharides. ${ }^{42}$ Results of conductometric titration indicated that Whatman CNCs had higher number of acidic groups than cotton CNCs, such that higher antiviral activity might have been expected. Although it was beyond the scope of this work to elucidate the mechanism of action of CNCs against SFV infection, the ineffectiveness of Whatman CNCs compared to cotton CNCs indicated that surface charge, and possibly particle size, played a critical role. Given the low rate of non-specific cellular uptake of $\mathrm{CNCs},{ }^{13}$ it could be argued that their mechanism of action was similar to that of other polyanionic compounds; via electrostatic binding to viral envelope glycoproteins, ${ }^{42}$ but this remains to be validated in our ongoing investigations.

The inherent property of CNCs to self-assemble into highly ordered liquid crystalline phases in aqueous media depends highly on the presence of electrolytes and other macromolecules. ${ }^{11}$, 12 This may suggest here that a lower number of acidic groups allowed CNCs to more effectively interact with the envelope of VA7-EGFP, thus inhibiting infection of host Vero (B) cells. In light of these results, cotton CNCs were chosen as the preferred substrate for further derivatization with tyrosine sulfate mimetic functionalities, as mentioned earlier. Additionally, desulfated cotton CNCs were tested at the highest concentration ( $0.36 \%$ wt.) as a potential negative control in comparison to CNCs bearing anionic functional groups. The preliminary result showed that desulfated CNCs also fully inhibited VA7-EGFP infection at this concentration, shown in Table S2. This was in agreement 
with the results of Serizawa et al. ${ }^{19}$ in which $0.5 \% \mathrm{w} / \mathrm{v}$ CNCs bearing only hydroxyl groups decreased bacteriophage infection of host E. coli. However, based on our later cell viability evaluations, desulfated CNCs were found to induce some degree of cytotoxicity compared to CNCs bearing anionic groups, therefore cell death could have also contributed significantly to the observed VA7EGFP inhibition (see Figure S2, Supporting Information). Furthermore, desulfated CNCs displayed the expected tendency to form large aggregates upon visual inspection, thus introducing an undesirable variable related to particle size. The focus of this study was to evaluate the effect of CNCs bearing different anionic functional groups on SFV inhibition, while avoiding potential effects caused by variations in particle size. Due to the tendency of desulfated CNCs to form large aggregates and their later demonstrated cytotoxicity, further inhibitory investigations were not carried out.

Shown in Figure 3 are the results of VA7-EGFP inhibition with two different batches of cotton CNCs bearing sulfate groups, CNCs bearing phenyl sulfonate groups (cotton-SPTC), and CNCs bearing phenyl sulfonate groups with molecular spacer “arms” (cotton-EBEA). For the sake of clarity, results of Whatman CNCs are not displayed here, but are found in Table S1. Regarding cotton CNCs bearing sulfate groups, our key observation was an abrupt decrease in viral activity at $0.14 \%$ wt. followed by nearly complete inhibition at $0.20 \%$ wt., which indicated non-linear kinetics. Similar responses were observed for both cotton CNC batches, with only small variations at 0.14 and $0.16 \%$ wt. Surprisingly, the abrupt decrease in viral activity was even more pronounced when VA7EGFP was incubated with CNCs bearing phenyl sulfonate groups (with and without EBEA molecular spacer). This result indicated a significant improvement in antiviral activity at concentrations $<0.20$ \% wt. The $\mathrm{EC}_{50}$ of various sulfated polysaccharides previously evaluated as SFV inhibitors was between 0.00007 to $0.028 \% \mathrm{w} / \mathrm{v}$, although they were also cytotoxic with $\mathrm{CC}_{50}$ concentrations as low as $0.05 \% \mathrm{w} / \mathrm{v}^{28}$ To the best of our knowledge, the inhibitory effect of CNCs has only been applied to a single non-enveloped bacteriophage, in which CNCs derived from tunicates and displaying only hydroxyl groups, decreased phage infection of host $E$. coli at a concentration of $0.5 \% \mathrm{w} / \mathrm{v} .{ }^{19}$ Cellulose 
sulfate was active against HIV-1 infection within concentration ranges of 0.001 to $0.1 \%$ w/v, above which was cytotoxic. ${ }^{43}$ Other types of polyanionic inhibitors developed as topical microbiocides have been formulated with high concentrations ranging from 0.5 to $6 \%$ wt., depending on polymer chemistry and molecular weight. ${ }^{42}$ According to our results, the antiviral activity of multivalent CNCs fell within a similar concentration range as other polyanionic inhibitors, however here we would like to highlight the effect of surface functionality on the same rod-shaped nanoplatform. Our observations suggest that conjugation of target-specific functionalities to CNC surfaces provides a means to control their antiviral activity. In this case, CNCs displaying phenyl sulfonate groups were approx. twice as effective as CNCs displaying sulfate groups on the inhibition of VA7-EGFP infection, as indicated in Figure 3. 


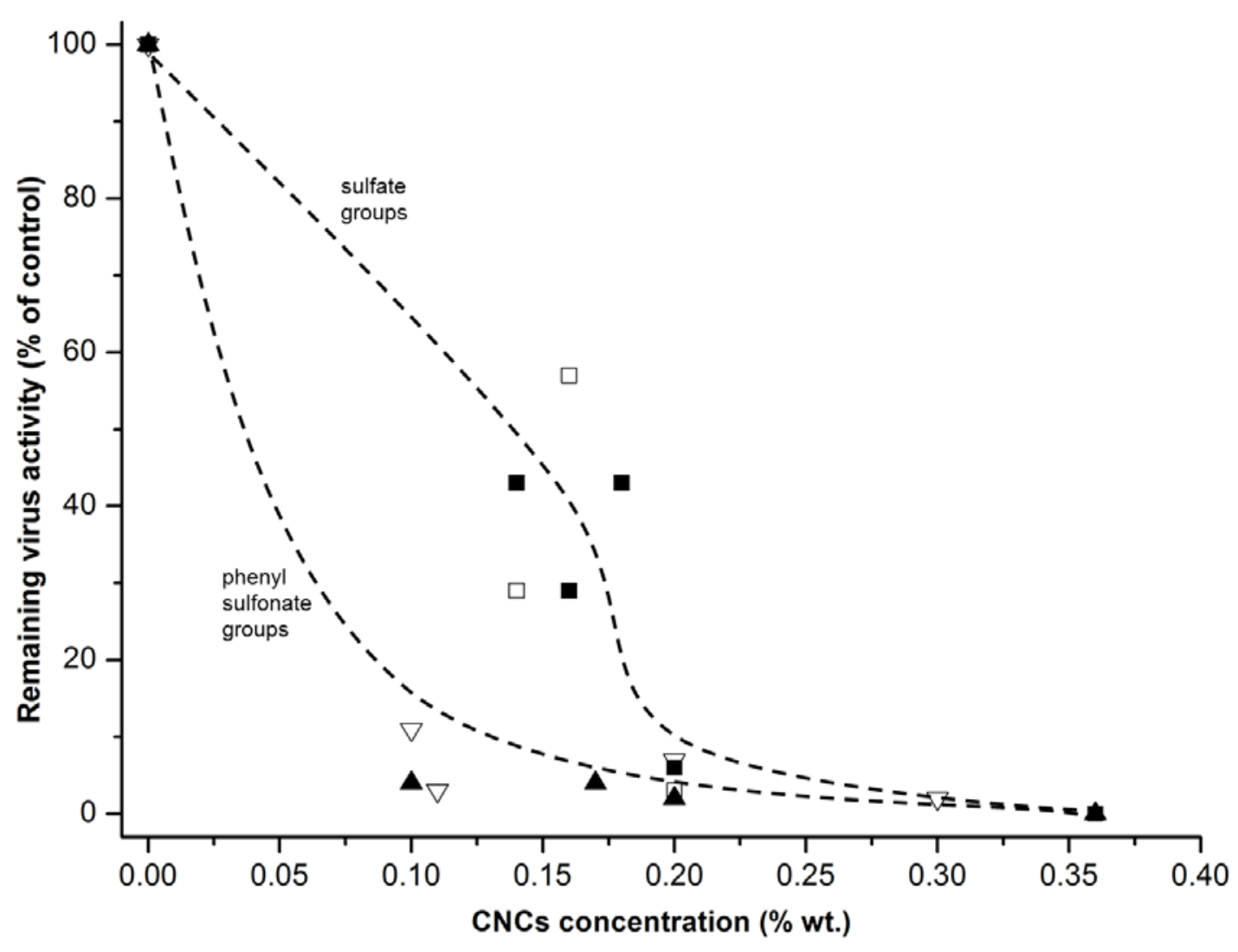

Figure 3. Influence of cotton CNCs bearing sulfate groups or phenyl sulfonate groups as a function of concentration on the inhibition of VA7-EGFP infection in vitro. Legend: cotton CNCs batch 1 ) and batch $2(\square)$, cotton-SPTC ( $\mathbf{\Delta})$ and cotton-EBEA $(\nabla)$. Note: Dotted lines drawn to guide the eye.

To determine whether the inhibitory effect of CNCs was dependent on VA7-EGFP concentration, CNC samples were incubated at $0.3 \%$ wt. with four different virus concentrations, from $3.25 \times 10^{5}$ to $3.25 \times 10^{8} \mathrm{PFU} / \mathrm{mL}$ (shown in Figure 4). At the lowest virus concentration, only $10 \%$ of viral activity remained in the presence of cotton CNCs, while cotton CNCs bearing phenyl sulfonate groups (cotton-SPTC) fully inhibited VA7-EGFP infection. When the virus concentration was increased by a factor of 10, viral activity was completed restored (100\%) even in the presence of cotton CNCs. In stark contrast, when the virus concentration was increased by a factor of 100 , cotton CNCs bearing phenyl sulfonate groups were still highly active at inhibiting VA7-EGFP infection (i.e. only $7 \%$ remaining viral activity). Only when the virus concentration reached $3.25 \mathrm{x}$ $10^{8}$ was viral activity completed restored in the presence of cotton CNCs bearing phenyl sulfonate 
groups, which further stressed the consequence of surface functionality on the inhibitory effect of CNCs. Moreover, preliminary inhibition assays were performed utilizing an alternative non-virulent SFV variant, rA774. ${ }^{39}$ Shown in Table S3 are the results of $0.36 \%$ wt. cotton CNCs, either desulfated or bearing phenyl sulfonate groups, on rA774 infection in vitro (Supporting Information). Both CNC samples were highly effective at inhibiting rA774 infection, which was a preliminary indication that CNC antiviral activity was not SFV variant-dependent. The antiviral activity of multivalent CNCs against other alphaviruses, lentiviruses and herpesviruses will be a topic of our future investigations.

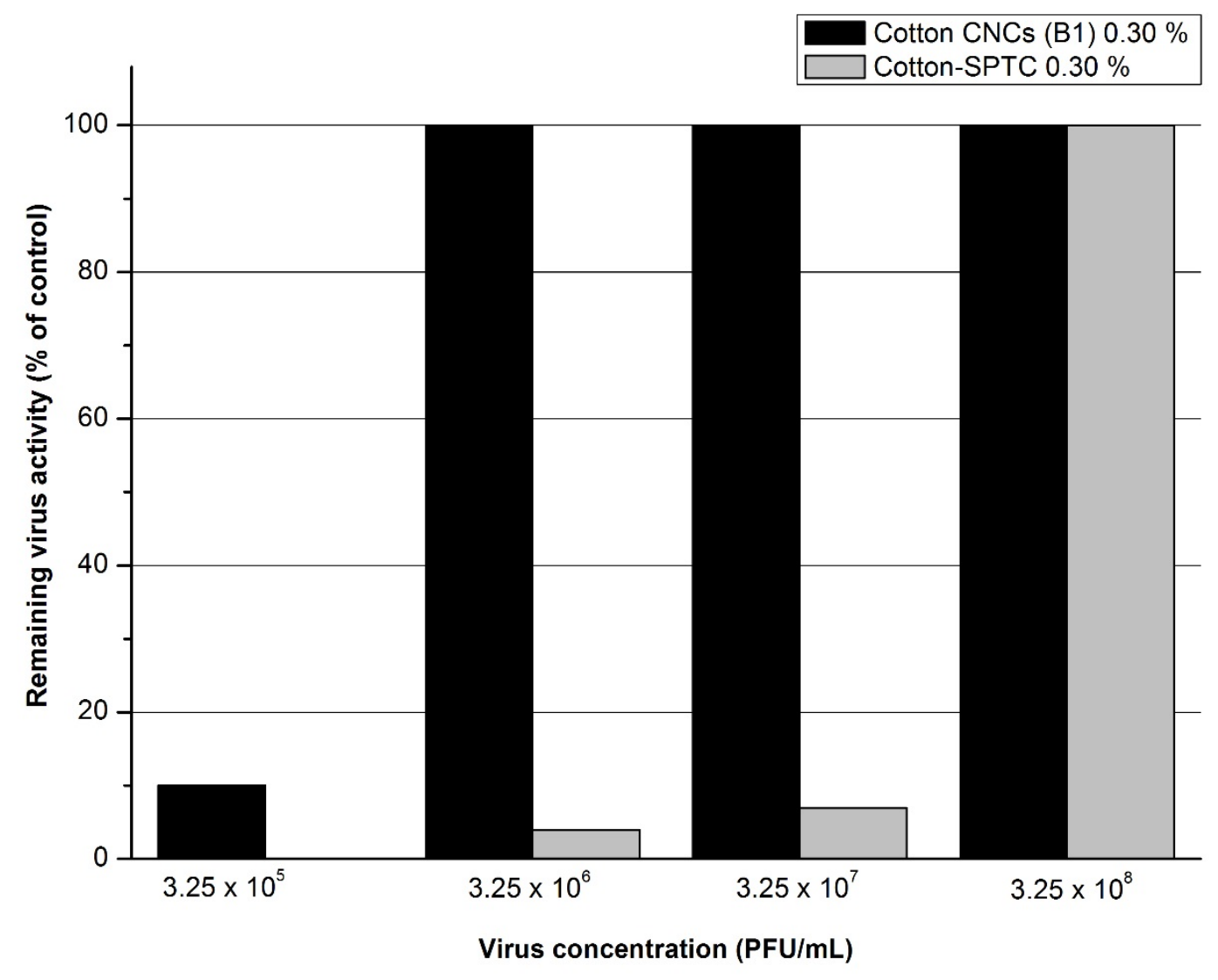

Figure 4. Influence of cotton CNCs bearing sulfate groups (black) and cotton CNCs bearing phenyl sulfonate groups (cotton-SPTC) (light grey) at $0.30 \%$ wt. on the inhibition of VA7-EGFP infection in vitro at different VA7-EGFP concentrations.

To ensure that the antiviral activity of CNC samples was not due to cytotoxicity, Vero (B) cells were treated with the CNC samples overnight. Then, cells were washed with phosphate buffer solution (PBS) followed by infection with VA7-EGFP. Infection was observed both in washed and unwashed (i.e. untreated) cells, thus CNC antiviral activity was not likely due to cell death. To 
further evaluate the cytotoxicity of CNCs samples, the sensitivity of HCE-T cells to the CNCs samples was determined using the CellTiter Blue ${ }^{\mathrm{TM}}$ assay. The studied samples included cotton CNCs bearing sulfate groups, Whatman CNCs bearing sulfate groups and cotton CNCs bearing phenyl sulfonate groups (with or without EBEA molecular spacer). After $1 \mathrm{~h}$ exposure, the mean HCE-T cell viability was $\geq 80 \%$ of the control level for all CNCs samples, even within the $100 \%$ virus-inhibitory concentrations, indicating their negligible effect on cell viability (Figure 5 and Figure 6). Dong et al. ${ }^{13}$ also found no cytotoxic effects of softwood pulp CNCs against nine different cell lines up to concentrations of $0.005 \% \mathrm{w} / \mathrm{v}$ via MTT assays. Furthermore, Ni et al. ${ }^{52}$ found $0.01 \%$ to $0.2 \%$ wt. CNCs derived from cotton linters had no cytotoxic effect on L929 cells via MTT assays, while at 1.0 \% cell viability was $70.9 \%$. It is noteworthy here that CNCs bearing anionic groups with concentrations up to $0.40 \%$ wt. showed no cytotoxic effects against HCE-T cells, as indicated by at least $80 \%$ of the control. In contrast, desulfated cotton CNCs were found to be cytotoxic within the same concentration range (shown in Figure S2), therefore further investigations on the inhibition of VA7-EGFP infection were not pursued. Male et $a l .{ }^{53}$ found low cytotoxicity of functionalized CNCs on two different cell lines, however they did show some inhibition and suggested a correlation with CNCs carboxylic acid content. On the other hand, the presence of anionic charges on nanoparticle surfaces has been suggested to reduce plasma protein adsorption and yield a low rate of non-specific cellular uptake, compared to neutral and positively charged nanoparticles. ${ }^{54}$ As highlighted earlier, our results indicated that surface functionality of CNCs played a critical role on SFV inhibition and could provide a means to control their antiviral activity. Here, we would like to illustrate the importance of anionic functional groups on CNCs surfaces in comparison to uncharged CNCs in governing their overall cytotoxicty, which was supported by previous investigations of sulfated CNCs. ${ }^{13}$ Here, since the effect of particle size could not be ruled out due to aggregation of uncharged CNCs, the effect of surface charge on cytotoxicity remains to be elucidated. 


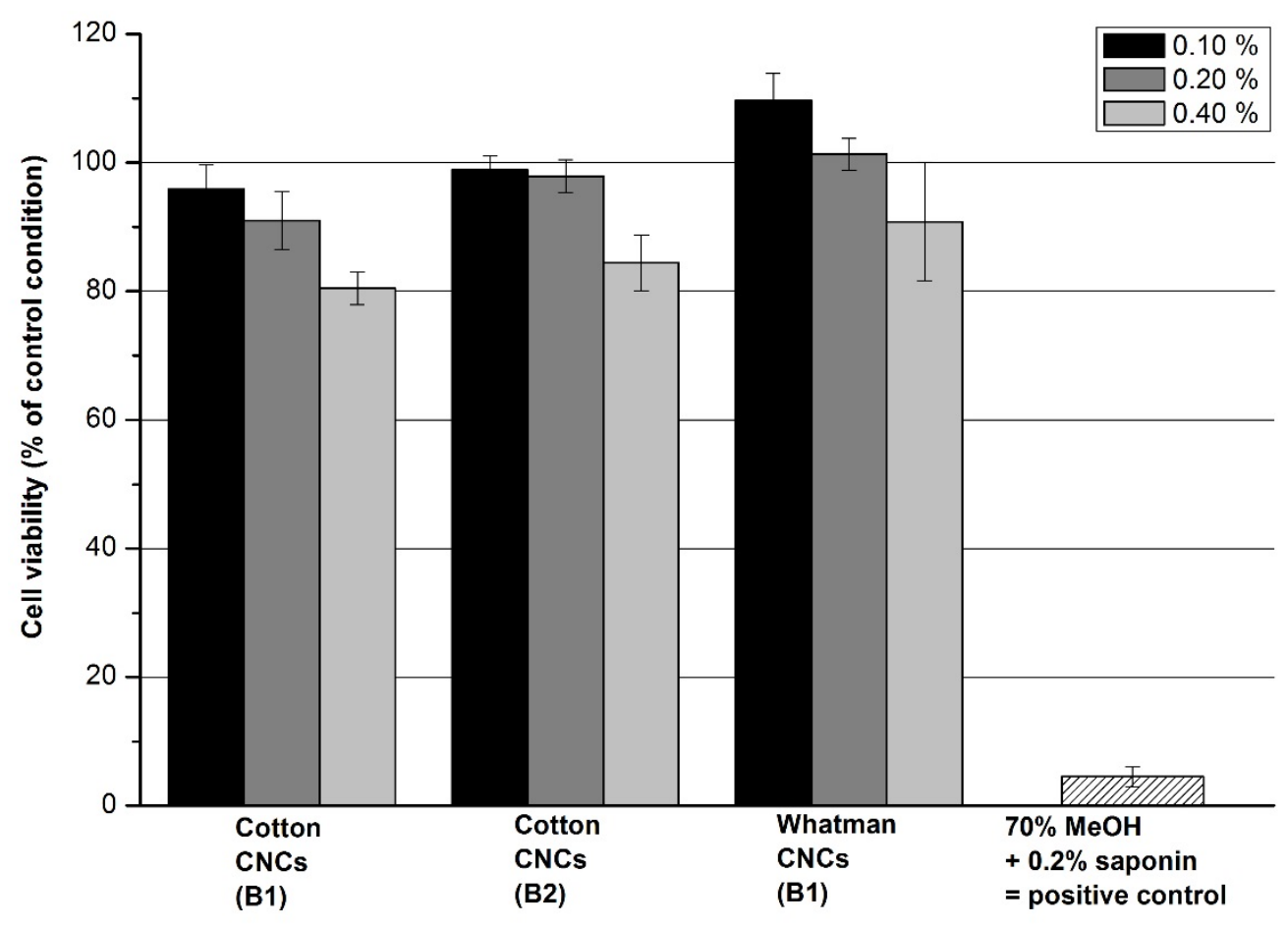

Figure 5. Effects of cotton CNCs bearing sulfate groups (batch 1 and 2) and Whatman CNCs (batch 1) bearing sulfate groups on human corneal epithelial (HCE-T) cell viability in vitro after 1 hour of exposure.

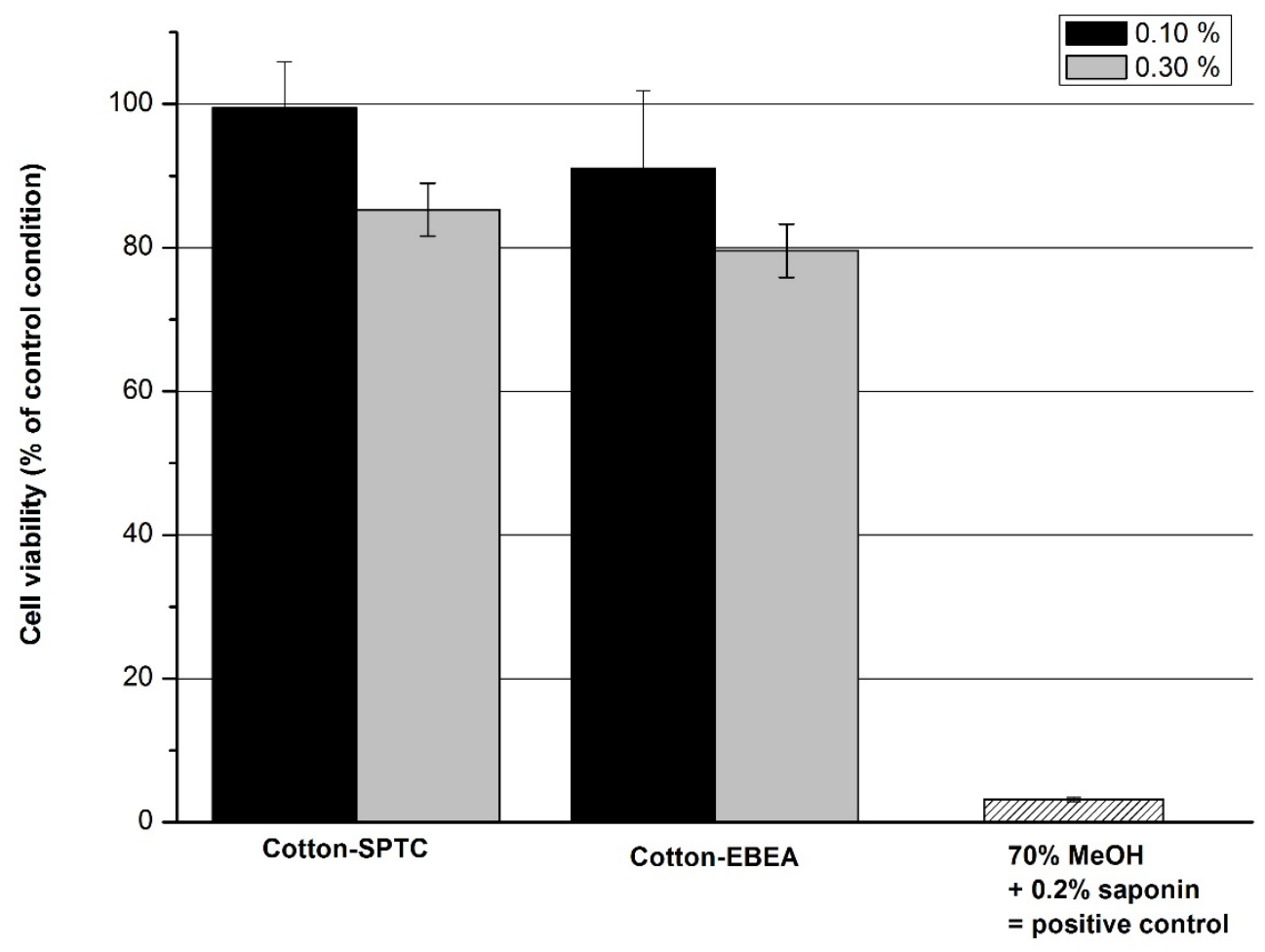

Figure 6. Effects of cotton CNCs bearing phenyl sulfonate groups (cotton-SPTC and cotton-EBEA) on human corneal epithelial (HCE-T) cell viability in vitro after 1 hour of exposure. 


\section{Conclusion}

We present two facile approaches for introducing multivalent displays of tyrosine sulfate mimetic ligands on the surface of cellulose nanocrystals for applications as viral inhibitors. Without modifications, cellulose nanocrystals prepared by sulfuric acid hydrolysis of cotton fibers or Whatman filter paper are also efficient inhibitors of alphaviral infection. Interestingly, CNCs bearing multivalent displays of tyrosine sulfate mimetic groups (with or without EBEA molecular spacer) were determined to increase their inhibitory effect. Our observations suggest that conjugation of target-specific functionalities to CNC surfaces provides a means to control their antiviral activity. Furthermore, all types of multivalent CNCs had a negligible effect on human corneal epithelial (HCET) cell viability in vitro. Since these compounds were determined to be non-cytotoxic, they could be used, for example, in combination with mosquito repellants providing safe, stable and low-cost nanomedicine potentially improving health in areas endemic to pathogenic alphaviruses. The observations of this study also suggest potential applications of CNCs as inhibitors of other viruses, such as HIV and Herpes simplex viruses. Given the well-known viral inhibitory properties of cellulose sulfate and sulfated polysaccharides, in general, it is expected that this study will provide the basis for further investigations on novel multivalent nanostructures for viral inhibiton based on CNCs. Ongoing investigations include synthesis optimization of multivalent CNCs, their selfassembly in the presence of alphaviruses, mechanism of action as well as the effect of aspect ratio and surface charge density on antiviral activity and cytotoxicity.

\section{Supporting Information}

Conductometric titration curves, alphavirus inhibition data tables, and cell viability assay of desulfated CNCs. This information is available free of charge via the Internet at http://pubs.acs.org. 


\section{Acknowledgments}

The authors would like to express their gratitude to Dr. Joseph Campbell for conducting

XPS measurements. The authors are grateful to Dr. Cristina Pérez Vera for reviewing the manuscript.

Funding support from Aalto University, the University of Eastern Finland, the Foundation for Finnish Inventions (Keksintösäätiö) and the Academy of Finland (Dec. No. 137759) are greatly appreciated.

\section{References}

(1) Wagner, V.; Dullaart, A.; Bock, A.-K.; Zweck, A., Nat. Biotechnol. 2006, 24, 1211-1217.

(2) Katz, E.; Willner, I., Angew. Chem., Int. Ed. 2004, 43, 6042-6108.

(3) Mammen, M.; Chio, S.-K.; Whitesides, G. M., Angew. Chem., Int. Ed. 1998, 37, 2755-2794.

(4) Weissleder, R.; Kelly, K.; Sun, E. Y.; Shtatland, T.; Josephson, L., Nat. Biotechnol. 2005, 23, 1418-1423.

(5) Baram-Pinto, D.; Shukla, S.; Gedanken, A.; Sarid, R., Small 2010, 6, 1044-1050.

(6) Baram-Pinto, D.; Shukla, S.; Perkas, N.; Gedanken, A.; Sarid, R., Bioconjugate Chem. 2009, 20, 1497-1502.

(7) Bowman, M.-C.; Ballard, T. E.; Ackerson, C. J.; Feldheim, D. L.; Margolis, D. M.; Melander, C., J. Am. Chem. Soc. 2008, 130, 6896-6897.

(8) Di Gianvincenzo, P.; Marradi, M.; Martinez-Avila, O. M.; Bedoya, L. M.; Alcami, J.; Penades, S., Bioorg. Med. Chem. Lett. 2010, 20, 2718-2721.

(9) Caruthers, S. D.; Wickline, S. A.; Lanza, G. M., Curr. Opin. Biotechnol. 2007, 18, 26-30.

(10) Boisselier, E.; Astruc, D., Chem. Soc. Rev. 2009, 38, 1759-1782.

(11) Habibi, Y.; Lucia, L. A.; Rojas, O. J., Chem. Rev. 2010, 110, 3479-3500.

(12) Moon, R. J.; Martini, A.; Nairn, J.; Simonsen, J.; Youngblood, J., Chem. Soc. Rev. 2011, 40, 3941-3994.

(13) Dong, S.; Hirani, A. A.; Colacino, K. R.; Lee, Y. W.; Roman, M., Nano LIFE 2012, 2, 1241006.

(14) Lam, E.; Male, K. B.; Chong, J. H.; Leung, A. C. W.; Luong, J. H. T., Trends Biotechnol. 2012, 30, 283-290.

(15) Rowe, R. C.; Sheskey, P. J.; Cook, W. G.; Fenton, M. E., Handbook of Pharmaceutical Excipients, 7th Edition. Pharmaceutical Press: London, 2012; p 1033.

(16) Dong, S.; Roman, M., J. Am. Chem. Soc. 2007, 129, 13810-13811.

(17) Burt, H. M.; Jackson, J. K.; Hamad, W. Y. Binding drugs with nanocrystalline cellulose excipient. WO 2012068670, 2012.

(18) Jackson, J. K.; Letchford, K.; Wasserman, B. Z.; Ye, L.; Hamad, W. Y.; Burt, H. M., Int. J. Nanomed. 2011, 6, 321-330.

(19) Serizawa, T.; Sawada, T.; Okura, H.; Wada, M., Biomacromolecules 2013, 14, 613-617.

(20) Ma, H.; Burger, C.; Hsiao, B. S.; Chu, B., Biomacromolecules 2012, 13, 180-186.

(21) Soumahoro, M.-K.; Gerardin, P.; Boelle, P.-Y.; Perrau, J.; Fianu, A.; Pouchot, J.; Malvy, D.; Flahault, A.; Favier, F.; Hanslik, T., PLoS One 2009, 4, e7800.

(22) Rezza, G.; Nicoletti, L.; Angelini, R.; Romi, R.; Finarelli, A. C.; Panning, M.; Cordioli, P.; Fortuna, C.; Boros, S.; Magurano, F.; Silvi, G.; Angelini, P.; Dottori, M.; Ciufolini, M. G.; Majori, G. C.; Cassone, A., Lancet 2007, 370, 1840-6. 
(23) Leparc-Goffart, I.; Nougairede, A.; Cassadou, S.; Prat, C.; de Lamballerie, X., Lancet 2014, 383, 514.

(24) Gibbons, D. L.; Vaney, M.-C.; Roussel, A.; Vigouroux, A.; Reilly, B.; Lepault, J.; Kielian, M.; Rey, F. A., Nature (London, U. K.) 2004, 427, 320-325.

(25) Lescar, J.; Roussel, A.; Wien, M. W.; Navaza, J.; Fuller, S. D.; Wengler, G.; Wengler, G.; Rey, F. A., Cell (Cambridge, MA, U. S.) 2001, 105, 137-148.

(26) Farzan, M.; Mirzabekov, T.; Kolchinsky, P.; Wyatt, R.; Cayabyab, M.; Gerard, N. P.; Gerard, C.; Sodroski, J.; Choe, H., Cell (Cambridge, Mass.) 1999, 96, 667-676.

(27) Acharya, P.; Dogo-Isonagie, C.; LaLonde, J. M.; Lam, S.-N.; Leslie, G. J.; Louder, M. K.; Frye, L. L.; Debnath, A. K.; Greenwood, J. R.; Luongo, T. S.; Martin, L.; Watts, K. S.; Hoxie, J. A.; Mascola, J. R.; Bewley, C. A.; Kwong, P. D., ACS Chem. Biol. 2011, 6, 1069-1077.

(28) Briolant, S.; Garin, D.; Scaramozzino, N.; Jouan, A.; Crance, J. M., Antiviral Res. 2004, 61, 111-117.

(29) Skoging, U.; Vihinen, M.; Nilsson, L.; Liljestroem, P., Structure (London) 1996, 4, 519-529.

(30) Zhao, H.; Lindqvist, B.; Garoff, H.; von, B., Carl-Henrik; Liljestrom, P., EMBO J. 1994, 13, 4204-11.

(31) Kloser, E.; Gray, D. G., Langmuir 2010, 26, 13450-13456.

(32) Ferreira, L. F. V.; Cabral, P. V.; Almeida, P.; Oliveira, A. S.; Reis, M. J.; Botelho do Rego, A. M., Macromolecules 1998, 31, 3936-3944.

(33) Nielsen, L. J.; Eyley, S.; Thielemans, W.; Aylott, J. W., Chem. Commun. (Cambridge, U. K.) 2010, 46, 8929-8931.

(34) Hermanson, G. T., Bioconjugate Techniques. 2nd ed.; Academic Press: London, 2008.

(35) Araki, J.; Wada, M.; Kuga, S.; Okano, T., Colloids Surf., A 1998, 142, 75-82.

(36) Johansson, L.-S.; Campbell, J. M., Surf. Interface Anal. 2004, 36, 1018-1022.

(37) Johansson, L.-S.; Campbell, J. M.; Koljonen, K.; Stenius, P., Appl. Surf. Sci. 1999, 144-145, 92-95.

(38) Beamson, G.; Briggs, D., High Resolution XPS of Organic Polymers: The Scienta ESCA300 Database. Wiley \& Sons: Chichester, England, 1992.

(39) Santagati, M. G.; Itäranta, P. V.; Koskimies, P. R.; Määttä, J. A.; Salmi, A. A.; Hinkkanen, A. E., J. Gen. Virol. 1994, 75, 1499-504.

(40) Araki-Sasaki, K.; Ohashi, Y.; Sasabe, T.; Hayashi, K.; Watanabe, H.; Tano, Y.; Handa, H., Invest. Ophthalmol. Vis. Sci 1995, 36, 614-21.

(41) Toropainen, E.; Ranta, V.-P.; Vellonen, K.-S.; Palmgren, J.; Talvitie, A.; Laavola, M.; Suhonen, P.; Hamalainen, K. M.; Auriola, S.; Urtti, A., Eur. J. Pharm. Sci. 2003, 20, 99-106.

(42) Pirrone, V.; Wigdahl, B.; Krebs, F. C., Antiviral Res. 2011, 90, 168-182.

(43) Yamamoto, I.; Takayama, K.; Honma, K.; Gonda, T.; Matsuzaki, K.; Hatanaka, K.; Uryu, T.; Yoshida, O.; Nakashima, H.; al., e., Carbohydr. Polym. 1991, 14, 53-63.

(44) Van Damme, L.; Govinden, R.; Mirembe, F. M.; Guedou, F.; Solomon, S.; Becker, M. L.; Pradeep, B. S.; Krishnan, A. K.; Alary, M.; Pande, B.; Ramjee, G.; Deese, J.; Crucitti, T.; Taylor, D.; Murphy, S.; Wahala, L.; Callahan, M.; Gabelnick, H.; Acevedo, N.; Johnson, L.; Dube, K.; Chalkley, L.; Carayon-Lefebre d'Hellencourt, F.; Combes, S.; Commins, M.; Tolley, E.; Corneli, A.; Law, M.; Rountree, W.; Saylor, L.; Fransen, K.; Beelaert, G.; Abdellati, S.; Mangelschots, M.; Buve, A.; Moses, S.; Blanchard, J.; Washington, R. G.; Satyanarayana, R.; Mendonca, K.; Minani, I.; Massinga Loembe, M.; Anagonou, S.; Geraldo, N.; Ganesh, A. K.; Johnson, S.; Vasudevan, C. K.; Murugavel, K. G.; Edward, V.; Raju, E.; Singh, R.; Vasant, U.; Khoza, N.; Ganesh, S.; Nakabiito, C.; Nakintu, N.; Tenywa, T.; Musuuza, C.; Nagganda, J.; Nakimuli, M.; Gati, B.; Kagoda, J.; Kaddu, R.; Kintu, G.; Luzze, M.; Saunders, C., N. Engl. J. Med. 2008, 359, 463-472.

(45) Zoppe, J. O.; Grosset, L.; Seppälä, J., Cellulose (Dordrecht, Neth.) 2013, 20, 2569-2582.

(46) Habibi, Y.; Hoeger, I.; Kelley, S. S.; Rojas, O. J., Langmuir 2010, 26, 990-1001. 
(47) Stone, M. J.; Chuang, S.; Hou, X.; Shoham, M.; Zhu, J. Z., New Biotechnol. 2009, 25, 299317.

(48) Smit, J. M.; Waarts, B.-L.; Kimata, K.; Klimstra, W. B.; Bittman, R.; Wilschut, J., J. Virol. 2002, 76, 10128-10137.

(49) Vonderheit, A.; Helenius, A., PLoS Biol. 2005, 3, 1225-1238.

(50) Li, Q.; Renneckar, S., Biomacromolecules 2011, 12, 650-659.

(51) Jiang, F.; Esker, A. R.; Roman, M., Langmuir 2010, 26, 17919-17925.

(52) Ni, H.; Zeng, S.; Wu, J.; Cheng, X.; Luo, T.; Wang, W.; Zeng, W.; Chen, Y., Bio-Med. Mater. Eng. 2012, 22, 121-127.

(53) Male, K.; Leung, A.; Montes, J.; Kamen, A.; Luong, J., Nanoscale 2012, 4, 1373-9.

(54) Alexis, F.; Pridgen, E.; Molnar, L. K.; Farokhzad, O. C., Mol. Pharmaceutics 2008, 5, 505515. 


\section{For Table of Contents Use Only}

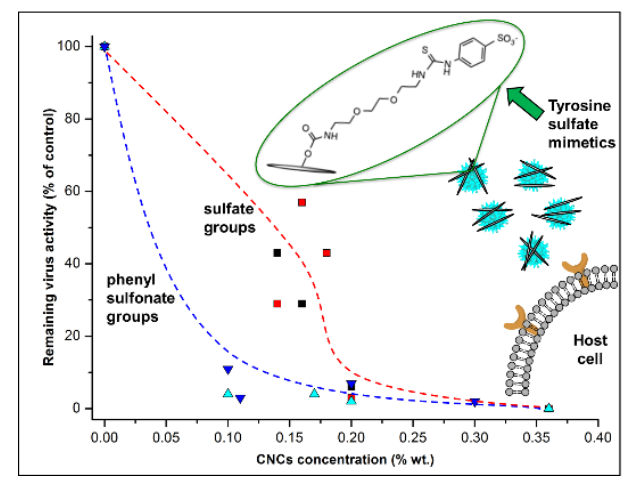

Manuscript Title: Synthesis of cellulose nanocrystals carrying tyrosine sulfate mimetic ligands and inhibition of alphavirus infection

Authors: Zoppe, Justin; Ruottinen, Ville; Ruotsalainen, Janne; Rönkkö, Seppo; Johansson, LeenaSisko; Hinkkanen, Ari; Järvinen, Kristiina; Seppälä, Jukka 